\title{
Enhancing the Pre-service Biology Teachers to Construct Better Lesson Plans: A Lesson Study
}

\author{
Huynh Thi Thuy Diem \\ School of Education, \\ Cantho University, Vietnam \\ Kongsak Thathong \\ Faculty of Education \\ Khon Kaen University, Thailand
}

\begin{abstract}
Lesson Study (LS) has been considered to be a novel approach to preparing and teaching lessons in the education system of Vietnam and applied to all schools nationwide. However, it has not been included in the educational teacher training curricula at the undergraduate level. Consequently, pre-service teachers may not only get a keen sense of what LS is but also face lots of trouble preparing an appropriate lesson plan (LP) which reflects the LS approach. Hence, this study aims at enhancing the pre-service biology teachers' (PBTs) understanding of the LS and developing the biology lesson plan (LP) by using the LS process. The research paradigm used in this phase is a mainly qualitative case study and a descriptive statistics design. Six female PBTs in their third year were chosen randomly from the volunteers to participate in the research. Before participating in the LS training workshop, the percentage of six PBT's understanding of the LS was at $0.0 \%$. However, after participating in the LS training workshops (LSTW), the six PBTs had a better insight into the LS and how to use the LS process to construct better biology LPs, which was proven by the average of $85.7 \%$. After participating in the LSTW, the entire PBTs recognized that LPs were team products and building better biology LPs was not so easy as it seemed. The LP was constructed based on the team collaboration in which all members shared their experiences.
\end{abstract}

Keywords: better lesson plans; lesson study; pre-service biology teachers; Vietnam.

\section{Introduction}

Previous studies have indicated that pre-service teachers are more than likely to face much trouble teaching in real classes due to the huge gap between their acquired theoretical knowledge and realistic experiences, Vietnamese preservice teachers are not an exception (Cabaroglu, 2014; Holt-Reynolds, 2000; 
Shchur, 2014; Thao-do, Bac-ly, \& Yuenyong, 2014). Indeed, besides lacking practical understandings and the ability to self-construct knowledge in their study, the Vietnamese PTs also need to improve their autonomy, creativity and problem-solving skills (Hung, 2006; Thanh, 2011). Also, in many burdens that hinder the PTs' efforts to fulfill themselves such as the lack of collaboration during the implementation of microteaching and practicum (Ho, Lap, \& Nam, 2012), lack of skills and insights to make proper observations and reflections (Borko \& Putnam, 1996; Ho H.T.T. et al., 2012), the strict control of the authorities in schools whose perspectives are rather conventional, the longrooted dependence on tests and examinations instead of meaningful teaching and learning, etc. (Wheeler, Hong, Chi, \& Ho, 2007).

Besides, when teaching, the PTs may face a great number of problems due to their novice status and their lack of feedback from those who have got more experience than them (Borko \& Putnam, 1996; Hammond, 1999, 2006). On the one hand, it helps the PTs construct better professional community, absorb the content and pedagogic knowledge more deeply, initiate the habit of observing, analyzing, and reflecting critically (Chassels \& Melville, 2009; Chokshi \& Fernandez, 2004; Groth, 2011; Tolle, 2010). Thanks to constructive feedback, the PTs may also turn their lessons to be more student-centered and improve their teaching skills in many aspects by themselves (Chassels \& Melville, 2009; M. L. Fernandez, 2005; Ganesh \& Matteson, 2010).

In 2014, Vietnam Ministry Education and Training (MOET) introduced two documentaries about using the LS in professional teacher meetings (PTMs) at high schools (MOET, 2014b, 2014a) in order to improve the quality of teaching and learning in Vietnam. As a result, LS has been widely applied in every subject in the whole country. In details, LS comprises (1) defining and researching a problem, (2) planning the lesson carefully, usually in collaboration with one or more colleagues, (3) observed by other teachers, and recorded particular issues happening in the class for analysis and reflection, (4) evaluating the lesson and reflecting on its effect, (5) revising the lesson, (6) teaching and observing the revised lesson, (7) evaluating and reflecting a second time, and (8) sharing the results (Clea Fernandez \& Yoshida, 2004; C. C. Lewis, 2002; C. Lewis \& Tsuchida, 1998; Mcmahon \& Hines, 2008; Saito \& Tsukui, 2008; Stigler \& Hiebert, 1999).

Furthermore, the LS has been proved to be a great way to enhance the teaching and learning quality. Indeed, it not only helps teachers fulfill their teaching skills but also facilitate better lessons. Moreover, with regard to learners, the LS also encourages teachers to care more about their students' real learning and serve as a catalyst for raising morale of the class (Allen, Donham, \& Tanner, 2004; Chikamori, Ono, \& Rogan, 2013; C. Lewis, Perry, \& Murata, 2006; Lukitasari, Susilo, Ibrohim, \& Corebima, 2014; Nurcahyo, 2005). Actually, using the LS offers many benefits for the PTs, such as (i) better understanding their students, (ii) the ability to see clearly the role of reflection from the peers (Chassels \& Melville, 2009; Ho et al., 2012); (iii) the improvement to their self-confidence in teaching, (iv) better understanding of different teaching and learning styles 
(Chassels \& Melville, 2009); (v) in-depth understanding of their subject matter knowledge (Chassels \& Melville, 2009; M. L. Fernandez, 2005; Ho et al., 2012). Thus, working on the LS process will help the better LP of PTs become more student-centered and improve the teaching skills (Chassels \& Melville, 2009; M. L. Fernandez, 2005; Ganesh \& Matteson, 2010; Ho et al., 2012).

Although being a potential strategy for professional teacher meetings (PTM) of all subjects at the high schools in Vietnam, particularly in order to increase teacher professional development, (MOET, 2013, 2014b, 2014a) the LS is still not yet mentioned in the MOET's teacher education training curriculum at the university. Therefore, the PBTs did not know about the LS and its process. As mentioned, the PBTs are likely to face numerous challenges in their future teaching. Besides, using the LS may affect the teachers' professional development. The focus of this paper is to describe the efficiency of the LS training workshop and using the LS model to enhance the PBTs' skills to construct better biology LPs. The findings of the study are important in determining the effectiveness of this model in helping PBTs to examine LS's understanding and enhance their practice.

The aforementioned characteristics are more likely to exist when it comes to teaching natural science subjects, especially the one feature both abstract concepts and longitudinal or micro phenomena like biology. Accordingly, this study was implemented to discover how to enhance Vietnamese PBTs' understanding of the LS and using it to improve construct better biology LPs.

\section{Research methodology}

\section{Research design}

The research employs a mainly qualitative case study and a descriptive statistics design (Cohen, Manion, \& Morrison, 2007). Both two approaches are utilized to analyze the current status of PBTs' understanding of the LS and investigate the opinions of the PBTs toward the LS after participating the LS training workshop by using multiple strategies such as questionnaire/ survey, participants' reflective writings, lesson plans, and recount/ retelling (Creswell, 2003, 2007) based on the LS approach (C. C. Lewis, 2002; Stigler \& Hiebert, 1999).

Besides the trainer, 3 scientific research experts in the field of education were invited to talk about their achievements on applying the LS in reality. The LS training workshop was set to take place in two mornings of two Saturdays, because it was convenient for both the experts and the PBTs to participate. During the workshop, the trainer provided the learners with opportunities to maximize their available experience through the learning activities so that they could enhance their thinking skills, particularly the creative thinking one. The main training method was constructivism, which was based on the prior and the sharing knowledge of the learners to construct new knowledge. Besides, the training method was also combined with lots of other methods such as sharing from experts, observing, discussing in groups, and especially the on-scene practice with the participants. 
The model of LS training workshop is graphically highlighted as follows in Figure 1

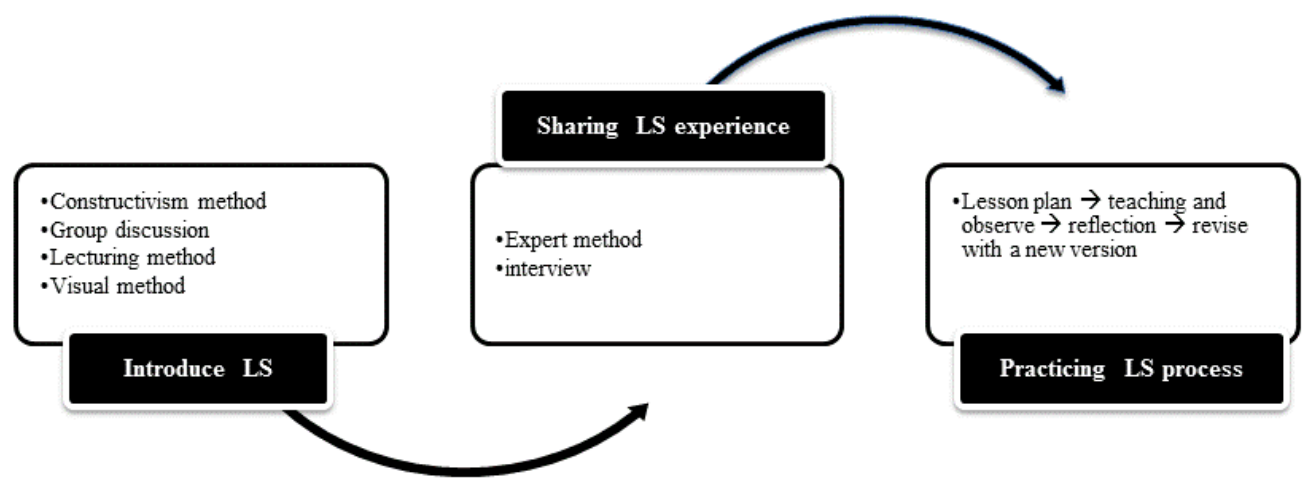

\section{Participants}

Figure 1:LS training workshop model

Six third-year female PBTs who have just finished learning about pedagogy theory and not yet taken any microteaching course were chosen randomly for the research to participate. Three of whom belong to minority groups using the LS to construct the LPs after participate LS training workshop.

\section{Tools/Instruments}

Before and after the workshop, the quantitative and qualitative questionnaires are admitted to PBTs. These questionnaires are used to investigate the knowledge toward the LS among the PBTs before and after they had participated in the LS workshop training. In addition, the PBTs are required to take participants' reflective writings after they had participated in the LS workshop training and microteaching. It was possible to identify the PBTs' understanding of the LS and to develop the biology LPs by using the LS process. When analyzing the PBTs' qualitative data, we did let them confirm the accuracy and validity of the records that we quoted.

\section{Data collection}

Before being put into use, we run the trial of the questionnaire on another group of students for amending and redesigning purposes. In that way, the questionnaire would be more appropriate for the targeted subjects. Our survey was designed to have three parts including (1) baseline characteristics of the PBTs, (2) opinions towards the LS model, and (3) the experienced PBTs' opinion about LS training activities. However, in the pre-test, the PBTs only answered the first two parts and PBTs' individual diary reflective writings were also made full use. Survey questionnaires were delivered directly to the six PBTs before and after the LS training workshop. The PBTs answered by writing their ideas in the paper questionnaire in about 20 minutes for the pre-test and send it to the researcher before the first training day. We held two weeks training sessions about the LS on two simultaneous Saturday. At the end of the last day, the posttest was carried out in about 40 minutes of the LS training workshop to examine the PBTs' knowledge regarding the LS as well as to evaluate the effectiveness of the training in the participating PBTs' personal and professional development. 
About the individual's diary reflective writings, PBTs submitted their reflective writing documents to an electronic mailbox.

\section{Data analysis}

The quantitative data were analyzed by applying descriptive statistics frequency and the qualitative data for the present study was interpreted, synthesized, and categorized following the same ideas. The quantitative and qualitative results were compared, integrated and interpreted by using convergence model of triangulation (Creswell, 2007). On the other hand, the constant comparative method (Glase \& Strauss, 1967) was applied for analyzing data. A combination of data from a different source was employed to ensure that the results would be valid and its cross-checking was reliable (Cohen et al., 2007; Patton, 2002). The results of this analysis will be discussed further in the next part.

\section{Results and Discussion}

\section{Enhancing the PBTs' understanding of the LS}

- Enhancing the PBTs' understanding of the LS theory

Featuring active teaching approaches such as active lecture, constructivism, expert sharing, experiment practice, group discussion, and observation, the workshop provided the participants with much useful knowledge related to the introduction of the LS history, definition and process, as well as the background, and the aims of the project. Noteworthily, the PBTs conceptions about the LS have been improved magnificently. Interestingly, there were also differences in the ratios of HSBTs' knowing LS before and those only knowing that after participating in the LS training workshop. Before six targeted PBTs participated in the LS training workshop, the percentage of PBTs' understanding of the LS was bottom-up at $(0.0 \%)$. No one knew or understood what the LS was. A common view among PBTs was that:

"I have not known about LS, how to reflect, think and receive reflecting feedback" (PBT-D ideas).

However, after participating in the LS training workshops, the PBTs had a better insight into the LS and how to use the LS process to construct better biology LPs, which made the figure peaked at $92 \%$ and reached the lowest point at $80 \%$, which average at $85.7 \%$.

The survey results on the PBTs' opinions about the definition of LS reveal that nearly all PBTs understood the LS and were capable of describing the stages of the LS model after participating in the training workshops. The opinions above prove that the knowledge related to the LS and the employed methods in the training were rather appropriate and effective. After the training, every PBT had a more profound point of view about LS. It should be applied regularly to enhance the professional capacity of teachers in specific and the education quality in general. A PBT wrote in her reflection,

"After the workshop, I could understand the LS perfectly. Lesson study will definitely help me a lot in my future career" (PBT-F's diary reflective writing). 
The survey results on the PBTs' reflections and thoughts about the training in the next part will cast light on what they acquired from the workshops.

- Enhancing for preparing LPS

Table 1: Comparison of the PBTs' ideas about preparing LPs before and after involving LS training workshop in survey

\begin{tabular}{|c|c|}
\hline $\begin{array}{l}\begin{array}{l}\text { Before involving LS training } \\
\text { workshop }\end{array} \\
\end{array}$ & After involving LS training workshop \\
\hline $\begin{array}{l}\text { I only knew how to design an } \\
\text { appropriate LP, follows the } \\
\text { regulations, addresses all contents in } \\
\text { the textbook, and that will meet the } \\
\text { requirements (PBT-C's idea). }\end{array}$ & $\begin{array}{l}\text { I know how to design LP which is } \\
\text { appropriate base on sharing experiences from } \\
\text { another teacher, address the important } \\
\text { contents, and what will meet the learner's } \\
\text { needs (PBTC's idea). }\end{array}$ \\
\hline $\begin{array}{l}\text { Mainly use the traditional methods to } \\
\text { lecture and impose students to learn } \\
\text { and to remember what the teacher } \\
\text { provides (The ideas of PBT-B, PBT-D } \\
\text { and PBT-F). }\end{array}$ & $\begin{array}{l}\text { The teacher would be able to choose many } \\
\text { methods and design an LP so that students } \\
\text { could construct new knowledge from } \\
\text { students' prior knowledge and set of leading } \\
\text { questions, rather than imposing students to } \\
\text { remember the knowledge by listening to the } \\
\text { lecture (The ideas of PBT-B, PBT-D, and PBT- } \\
\text { F). }\end{array}$ \\
\hline $\begin{array}{l}\text { The duty of preparing LP is only done } \\
\text { by individuals who directly teach in } \\
\text { his or her class. (PBT-A's idea) }\end{array}$ & $\begin{array}{l}\text { Preparing LP embraces sharing experience } \\
\text { among teachers who have been teaching such } \\
\text { as student's misunderstandings, students feel } \\
\text { difficulties while learning LP (PBT-A's idea). }\end{array}$ \\
\hline $\begin{array}{l}\text { "Actually, I have never thought about } \\
\text { what problems students face when } \\
\text { they attend my lecture. I myself } \\
\text { thought that LP design is a simple job } \\
\text { that we just need to provide the } \\
\text { knowledge to students, help them to } \\
\text { know and memorize, and that is } \\
\text { enough" (PBT-E's ideas). }\end{array}$ & $\begin{array}{l}\text { We focus what on students need, how to } \\
\text { make their understanding, how to leave them } \\
\text { the impressions of the knowledge and why } \\
\text { they have to learn and how come they } \\
\text { confuse or don't understand the issues. (The } \\
\text { ideas of PBT-A, PBT-B and PBT-E) }\end{array}$ \\
\hline
\end{tabular}

As shown in the findings (Table 1), before the training, $100 \%$ of the PBTs considered lesson planning to be a simple and somehow mundane task which heavily depended on regulations, textbook contents, and prescriptive approach. This may be because the PBTs get so familiar with the teaching methods that they were taught at high school. As pointed out in many studies (Saito, Tsukui, \& Tanaka, 2008; Stigler \& Hiebert, 1999), most teachers employed teaching methods which have been imparted from previous generations. However, after the training, the PBTs have found much interesting knowledge of preparing LP such as collaboratively working, sharing experience, student-centered teaching, students' understanding and impression the knowledge, which have been mentioned in some previous research (Clea Fernandez \& Yoshida, 2004; C. C. Lewis, 2002; Stigler \& Hiebert, 1999). This result shows that the PBTs have realized the benefits of collaborating to design the LPs that fulfill the learners' needs and improve their outcomes after receiving the training. 
- Enhancing observation skills

Before involving LS training, some of them did not have a favored preference for class observation as shown in the PBTs' answer in the survey:

"I dislike it because after the observation, the observers will show me my mistakes in teaching and I have to prepare the LP carefully by tenfold as usual" (PBT-E's idea).

"I don't like observation because it makes me unconfident, confused and makes the atmosphere stressful and uncomfortable" (PBT-F's idea).

"I do not like class observation because it will cause pressure on both the students and the teacher, it will make the class uncomfortable, and the class atmosphere will be stressful (PBT-A, PBT-B and PBT-E). If the students want to answer something, they must be sure about the answer to volunteer. They will not dare to discuss or ask the teacher what they do not know. The classroom atmosphere will be stressful" (PBT-A's idea).

It may be because they were afraid that this method would put both the students and the teachers under pressure, and turn the class atmosphere to be stressful. However, they also favored some aspects of the observation because they could receive feedback about their mistakes or limitations from observing teachers.

This is similar to the opinions of many other HSBTs participating in this research. Because of the similarities between the culture and reality in Vietnam and those in the US (Chassels \& Melville, 2009; Sonal Chokshi \& Fernandez, 2004) which consider teaching as individual work, the teachers do not like being observed, commented or evaluated. Moreover, LPs are usually prepared by the observed teacher only, so the observing teachers are likely to focus on the teaching quality rather than the students' learning.

Surprisingly, after trained at the workshops, PBTs seemed to have a better attitude toward the observation activity.

They appreciated the necessity and significance of the observation in shedding light on the students' learning and the quality of class activities. Indeed, they realized that the observation was a group activity rather than an individual one of the observed teachers only. Besides, the observation also helped to collect data and evidence which would contribute to better feedback (Stigler \& Hiebert, 1999).

\section{- Enhancing reflection skills}

Most of the PBTs like people to reflect on their teaching before and after the LS training workshop. These results are not surprising because they are still novices, so they need reflections to improve their teaching knowledge and skills both before and after participating in the LS training workshop. However, they just simply thought that the feedback would benefit the teachers-in-charge only. "I like and want other people to reflect on my teaching. Therefore, I know my strengths to foster and weaknesses that I cannot realize by myself when I teach in order to improve" (PBT-B's idea). 
"I like reflection because when being reflected, I can overcome my shortcomings, foster my strengths and learn from the experience as well as prepare for the next lesson better" (PBT-E's idea).

"I like receiving reflection for my teaching because compliments or critical feedback teach me how to do better in the next time" (PBT-A, PBT-F and PBT-D ideas).

"I also realized that the purpose of reflection is to develop a better LP for the whole group, and it is not about the teacher only. This purpose makes the reflections unpressured and unstressful" (PBT-F's idea).

"I like reflection because the atmosphere of the reflection is sincere, open to developing a better LP for the whole teacher group" (PBT-E's idea).

Reflections are not oriented to the whole group but some individuals. Hence, the feedback givers just base on their viewpoints and the feedback receivers' comments were also concentrated on themselves.

Yet after the training about the LS, all of the PBTs recognized that reflections which were based on the teachers' perspectives improved the quality of the LPs and the plans themselves were the products of the whole group rather than just an individual. Some PBTs felt that

"I like a reflection of my teaching because it is a chance to share, learn from the experience of each other, to understand deeper about my specialized knowledge as well as develop my teaching skills" (PBT-C's idea).

"It is also a chance for teachers to discuss together to find out better solutions for shortcomings in teaching" (PBT-B's idea).

"The reflection is not to evaluate the teacher, although the observed teacher did not do the teaching well, it is also a valuable lesson for the whole group, and from that, the group can find out the solutions for the problems together" (PBT-A, PBT-F, PBT-B, PBT-D, and PBT-E ideas).

These results are consistent with those of other studies (Clea Fernandez \& Yoshida, 2004; C. Lewis \& Tsuchida, 1998; Stigler \& Hiebert, 1999). On the other hand, reflection activity helps group members to understand more about one another and bring fewer problems and less pressure on their colleagues. Also, most of PBTs' opinions were based on a sharing, collaborative and helpful spirit, which helped find out new teaching methods and better LPs. Moreover, reflections have no longer been an obsession or pressure put on the teachers. Giving reflections has turned out to be a cozy, friendly sharing meeting in which the participants give open and supportive recommendations. Besides, reflection by many people will provide many comments and evaluate the overall problem in many aspects, as each person has his good way to construct a better and livelier LP together and reinforce the close-knit relationship among the group 
members as having stated in a previous study (Saito et al., 2008). Most of PBTs understood that in the reflection stage, the observing teachers do not force the observed teacher-in-charge to teach in a particular way but place themselves in the colleagues' position to find out the solutions to difficulties during the teaching; as a result, the lessons may become more effective and attractive. Although the representative teacher did not do the teaching well, it is also a valuable lesson for the whole group, and from that, the group can find out the solutions for the problems together like the previous study (C. C. Lewis, 2002).

\section{The impacts of using the LS in microteaching to PBTs}

From microteaching observation and reflection results, it seems that applying the LS in microteaching did help the PBTs enhance their capacity to prepare the LPs; their teaching skills; even widen their subject matter knowledge. These improvements have a tremendously positive impact on the PBTs' profession.

\section{- Enhancing for preparing LPS}

Progressively, the PBTs' skills, especially the ones regarding the LPs were improved after each step of the LS. As reflected in the LPs, PBTs have learned a lot of experience in designing an LP-based LS process. For the first time, for preparing the LP, the PBTs started with discussions about lesson objectives. However, in the second time, they paid more attention to the teachers' obstacles and difficulties. In the third time, difficulties that the teachers and students had faced were taken into account first. Then the whole group analyzed the lesson to find taxing contents to the students. This improvement has been proved in the PBT-B's feedback:

"Previously, when starting to design a microteaching LP, I usually consulted many materials like teacher's books, the handbook of standard knowledge for high school students, model LPs on the internet to compose the lesson objectives, methods, means and teaching progress" (PBT-B's diary reflective writing).

"Now, in the reflection stage, every PBT who conduct the LP first has to share what obstacles she was faced, what difficulties of students have while learning the lesson as well as what knowledge the students may have already known. Then we start to discuss the students' expectations from the lesson; and find the solutions to solve the students' difficulties. In fact, they are usually caused by their inability to give correct answers to teacher's questions or they do not know how to describe the picture or make a conclusion of what they have observed" (All of PBTs' diary reflective writing).

Besides, the PBTs have learned a lot of experience related to how to design a detailed LP with purposes, outline, keyword analysis, forming questions, which is the most scientific-based and concise way for students to understand. Especially, the most important experience for them was how to teach definitions effectively. They had spent more time thinking to find the way to implement the lesson effectively and drew some notices about teaching a concept as reflected in the two following PBTs' sharing: 
"I realize that I am supposed to follow the same procedures no matter what biology knowledge unit I have to teach, i.e. (1) Determine keywords or the focus of the definition, (2) Find images or appropriate teaching aids to illustrate the knowledge which we need to impart. (3) Find out the most relevant questions that lead students from the unknown things to the understandable ones and form new knowledge" (Diary reflective writings of all PBTs).

In the lessons learned that the PBTs shared, the LPs were shown clearly through the following teaching skills.

- Enhancing teaching skills

As shown in the PBTs' feedback diaries and comments after each time, the results prove that the PBTs have obtained lots of active teaching skills such as how to make the students involved in the lesson, and how to present the lesson on the board. For example, one PBT started the lesson with issues related to the real life of the students to arouse their curiosity and drew their attention to the lesson. Plus, they also knew how to build productive questions and manipulate teaching aids effectively. For instance, a PBT has brought a real pumpkin to her class and used these questions for the lead-in of her lesson:

"This morning, I bought something at the market. What is it? What can we find more in this pumpkin? Who knows how this pumpkin is formed? How are the seeds formed? Do you want to know?" (PBT-B's diary reflective writing).

Moreover, previously, the questions had been so general and highly prescriptive. The teachers sometimes concluded that instead of letting their students do it on their own and in that way acquire new knowledge. Nonetheless, most of the PBTs have doubted this mundane method after the workshop and the microteaching. A PBT has revealed:

"I learn teacher provide opportunities to help students think and to learn by themselves by including expanding questions to make the lesson more meaningful" (PBT-B's diary reflective writing).

- Enhancing subject matter knowledge

As reflected in the PBTs' sharing, the subject matter knowledge of the PBTs have been gradually improved after taking microteaching and reflection three LPs. For example, a PBT has shared in her reflection what she acquired as follows.

"So far, I usually write the fertilization plan as follows: Male gamete ( $n$ )

+ Female gamete $(n) \rightarrow$ Zygote (2n). Thanks to the explanation of the researchers in the reflection meeting. I could understand deeply to recognize our mistake and how to write a hybrid map scientifically and accurately. In the hybrid map or fertilization diagram, we use the sign " $x$ " correctly instead of the wrong one - " + " and now I can be confident to clarify why we have to write " $x$ "" (Diaries of all PBTs).

These results concerning the PBTs' skills to manipulate teaching aids effectively had already been proved in previous studies (Ho et al., 2012). These results are consistent with those of other studies in improving teaching skills and changing 
teachers' performance (Chassels \& Melville, 2009; C. Fernandez, 2002; Ganesh \& Matteson, 2010; C. Lewis et al., 2006; J. M. Lewis, Fischman, Riggs, \& Wasserman, 2013; Nurcahyo, 2005; Saito, Harun, Kuboki, \& Tachibana, 2006; Sims \& Walsh, 2009). Similar to previous studies (Beyer, Dalgado, Davis, \& Krajcik, 2007; Fatima Shakil, Faizi, \& Hafeez, 2011; Ho et al., 2012), although the PBTs may encounter a great number of challenges in the first times they taught, their capacity to handle the confusion has become more and more enhanced in later times. This signified that the LS model had contributed to better LPs. PBTs were not only more confident in dealing with problems but also proactive in creating a fun and friendly learning atmosphere, as well as clever in responding to the students' questions.

\section{Conclusions}

As demonstrated and discussed, the results of this study have ascertained the value of the LS, especially in the context of Vietnam. Learning activities in the workshops which were focused on the steps of the LS were pivotal in helping the PBTs comprehend the LS and realize its values, especially in terms of their professional development. Applying the LS model in microteaching, the PBTs had another chance to practice the skills of designing LPs, teaching and engaging the students in the lesson in a natural way. Skills of teaching concepts, posing effective questions and associating them with teaching aids were also enhanced. In microteaching, the PBTs had an opportunity to widen their knowledge and understanding of the lessons through sharing and analyzing lesson plans after observing. Microteaching was to help the teachers prepare better LPs with effective teaching methods, abundant knowledge and a comprehensible approach which allows the students to absorb easily, and recognize the lesson values. As the PBTs' opinions reflect, it seems that they adequately understood the LS. They realized that they had changed their minds after the training, which covered activities of teaching, construct lesson plan together, observing and giving feedback. Besides, their subject matter knowledge has also been magnificently improved. Smooth and good as it seemed, the researchers of this study also realized some limitations that should be avoided in futures research. Indeed, it would have been better if all of the participants' feedback and reflection in the workshop had been taken into account, which could make the results and discussion more objective and comprehensive.

\section{References}

Allen, D., Donham, R., \& Tanner, K. (2004). Approaches to biology teaching and learning: LessonsStudy--building communities of learning among educators. Cell Biology Education, 3, 1-7. doi:10.1187/cbe.03-12-0028

Beyer, C. J., Dalgado, C., Davis, E. A., \& Krajcik, J. S. (2009). Investigating teacher learning supports in high school biology textbooks to inform the design of educative curriculum materials. The April 2007 Annual Meeting of the National Association for Research in Science Teaching, New Orleans, 1-30. doi:10.1002/tea.20293

Borko, H., \& Putnam, R. T. (1996). Learning to teach. Hand Book of Educational Psychology, 673-708.

Cabaroglu, N. (2014). Re-visiting the theory and practice gap through the lens of student teacher dilemmas. Australian Journal of Teacher Education, 39(2), 89-149. 
doi:10.14221/ajte.2014v39n2.10

Chassels, C., \& Melville, W. (2009). Collaborative, reflective, and interative Japanese lesson study in an initial teacher education program: Benefits and challenges. Canadian Journal of Education, 32(4), 734-763.

Chikamori, K., Ono, Y., \& Rogan, J. (2013). A lesson study approach to improving a biology lesson. African Journal of Research in Mathematics, Science and Technology Education, 17, 14-25. doi:10.1080/10288457.2013.828408

Chokshi, S., \& Fernandez, C. (2004). Challenges to importing Japanese lesson study: Concerns, misconceptions, and nuances. Phi Delta Kappan, 85(7), 502. doi:10.1177/003172170408500710

Cohen, L., Manion, L., \& Morrison, K. (2007). Research Methods in Education. In Routledge, London and New York. doi:10.1080/19415257.2011.643130

Creswell, J. W. (2003). Research design. Qualitative, Quantitative, and Mixed methods approaches. Research Design, 86, 1-26. doi:10.4135/9781849208956

Creswell, J. W. (2007). Qualitative inquiry and research design: Choosing among five approaches. Sage Publiscation. doi:10.4135/97814129862681.n304

Fatima Shakil, A., Faizi, W-N., \& Hafeez, S. (2011). The need and importance of field trips at higher level in Karachi, Pakistan. International Journal of Academic Research in Business and Social Sciences, 2(1), 1. Retrieved from www.hrmars.com

Fernandez, C. (2002). Learning from Japanese Approaches to Professional Development: The Case of Lesson Study. Journal of Teacher Education, 53, 393-405. doi:10.1177/002248702237394

Fernandez, C., \& Yoshida, M. (2004). Lesson study a Japanese approach to improving mathematics teaching and learning. Lawrence Erlbaum Associates, Inc.

Fernandez, M. L. (2005). Exploring "lesson study" in teacher preparation. Proceedings of the 29 Th Conference of the International Group for the Psychplogy of Mathematics Education, 2, 2-305.

Ganesh, B., \& Matteson, S. M. (2010). The benefits of reteaching lessons in preservice methods classes. Action in Teacher Education, 32(May 2015), 52-60. doi:10.1080/01626620.2010.549718

Glase, B. G., \& Strauss, A. L. (1967). The discovery of grounded theory: strategies for qualitative research. In Statewide Agricultural Land Use Baseline. doi:10.1017/СBO9781107415324.004

Groth, R. E. (2011). Improving teaching through lesson study debriefing. Mathematics Teacher, 104(6), 446-451.

Hammond, L. D. (1999). Aligning teacher education with contemporary K-12 reform visions. In L. Darling-Harmond \& G. Sykes (Eds.), Teaching as the learning profession: Handbook of policy and practice (pp. 33-53). San Francisco: Jossey-Bass.

Hammond, L. D. (2006). Powerful teacher education: lessons from exemplary programs. Jossey-Bass.

Ho, H. T. T., Lap, T. Q., \& Nam, N. thi H. (2012). Applying lesson study in microteaching for teacher education in a Vietnamese context. Case study in a Geography micro-teaching course in Can Tho University-Vietnam. The World Association of Lesson Study (WALS) 2012 International Conference, November 28-30, Singapore.

Holt-Reynolds, D. (2000). What does the teacher do? constructivist pedagogies and prospective teachers' beliefs about the role of a teacher. Teaching and Teacher Education, 16, 21-32. doi:10.1016/S0742-051X(99)00032-3

Hung, L. N. (2006). An overview of Vietnamese higher education in the era of globalization: Opportunities and challenges. Essays In Education Journal, 18(13). doi:10.1024/0301-1526.32.1.54 
Lewis, C. C. (2002). Brief guide to lesson study. In Philadelphia: Research for Better Schools.

Lewis, C., Perry, R., \& Murata, A. (2006). How should research contribute to instructional inprovement? The case of lesson study. Educational Researcher, 35, 314. doi:10.3102/0013189X035003003

Lewis, C., \& Tsuchida, I. (1998). A lesson is like a swiftly flowing river how research lessons improve Japanese education. Improving Schools 2(1), 48-56. doi:10.1177/136548029900200117

Lewis, J. M., Fischman, D., Riggs, I., \& Wasserman, K. (2013). Teaching learning in Lesson study. The Mathematics Enthusiast, 10(3), 583-620.

Lukitasari, M., Susilo, H., Ibrohim, \& Corebima, A. D. (2014). Lesson study in improving the role of e-Portfolio on the metacognitive skill and concept comprehension: A study on cell biology subject in IKIP PGRI Madiun, Indonesia. American Journal of Educational Research, 2(10), 919-924. doi:10.12691/education-2-10-11

Mcmahon, M. T., \& Hines, E. (2008). Lesson study with pre-service teachers. Mathematics Teacher, 102(3), 186-191.

MOET. (2013). Tập huấn tổ trương chuyên môn cấp trung học phổ thông (p. 131). p. 131.

MOET. (2014a). Công văn hướng dẫn thự hiện nhiệm vụ Giáo dục trung học năm học 20142015 [Dispatch No: 4099/BGDĐT-GDTrH on the guiding carry out high school education duties in the academic year of 2014-2015] (pp. 1-9).

MOET. (2014b). Dispatch No: 5555/BGDĐT-GDTrH on the "Guiding professional teacher meeting about teaching methods renovation and testing, assessment; organizing and management of professional activities of high school/web continuing educational center (Vietnamese) (pp. 1-5).

Nurcahyo, H. (2005). Improving biological science teacher competencies through applying lesson study. 1-9.

Patton, M. Q. (2002). Qualitative research \& evaluation methods (p. 690). Sage Publications. Thousand Oaks. London. New Delhi.

Saito, E., Harun, I., Kuboki, I., \& Tachibana, H. (2006). Indonesian lesson study in practice: case study of Indonesian mathematics and science teacher education project. Journal of In-Service Education, 32(2), 171-184. doi:10.1080/13674580600650872

Saito, E., \& Tsukui, A. (2008). Challenging common sense: Cases of school reform for learning community under an international cooperation project in Bac Giang Province, Vietnam. International Journal of Educational Development, 28, 571-584. doi:10.1016/j.ijedudev.2007.12.006

Saito, E., Tsukui, A., \& Tanaka, Y. (2008). Problems on primary school-based in-service training in Vietnam: A case study of Bac Giang province. International Journal of Educational Development, 28(1), 89-103. doi:10.1016/j.ijedudev.2007.08.001

Shchur, N. (2014). Pre-Service biology teacher preparation in the Usa and Ukraine: Comparative study of professional education training. American Journal of Educational Research, 2(5), 278-282. doi:10.12691/education-2-5-7

Sims, L., \& Walsh, D. (2009). Lesson study with preservice teachers: Lessons from lessons. Teaching and Teacher Education, 25(5), 724-733. doi:10.1016/j.tate.2008.10.005

Stigler, W. J., \& Hiebert, J. (1999). The teaching gap: Best ideas from world's teacher for improving education in the classroom. doi:10.1080/00220270050167215

Thanh, N. C. (2011). Training high qualified teachers in Vietnam: Challenges and policy issues. University of Education, Vietnam National University at Ha Noi, Vietnam, 197213.

Thao-do, T. H. I. P., Bac-ly, D. T. H. I., \& Yuenyong, C. (2014). Learning environment in vietnamese physics teacher education programme through the lens of constructivism: a case study of a state university in mekong delta region, vietnam. 
International Journal of Science and Mathematics Education, 14(1), 55-79 doi:10.1007/s10763-014-9585-2

Tolle, P. P. (2010). Lesson study: Still a work in progress in America. Mathematics Teacher, 104(3), 181-185.

Wheeler, C. W., Hong, P. T. N., Chi, B. L., \& Ho, H. T. T. (2007). Lesson study,

Vietnamese style: bringing meaning to a hollow shell. World Association of Lesson Studies International Conference., 1-14. 